\title{
Mindfulness-Based Cognitive Therapy Versus Treatment as Usual in Adults with ADHD: a Trial-Based Economic Evaluation
}

\author{
Lotte Janssen ${ }^{1}$ (D) Janneke P. C. Grutters ${ }^{2}$ - Melanie P. J. Schellekens ${ }^{1} \cdot$ Cornelis C. Kan $^{1}$ • Pieter J. Carpentier ${ }^{3}$. \\ Bram Sizoo $^{4} \cdot$ Sevket Hepark $^{1} \cdot$ Jan K. Buitelaar ${ }^{5,6} \cdot$ Anne E. M. Speckens $^{1}$
}

Published online: 23 March 2019

(C) The Author(s) 2019

\begin{abstract}
Objectives ADHD has a considerable economic impact. The aim of this study is to conduct a trial-based economic evaluation of mindfulness-based cognitive therapy (MBCT) added to treatment as usual (TAU) versus TAU in adults with ADHD.

Methods A Dutch economic evaluation with a time horizon of 9 months was conducted from the societal perspective in the intention-to-treat (ITT) sample. Costs were assessed with a self-report questionnaire. Outcomes were expressed in quality adjusted life years (QALYs) and response rate. Bootstrap simulations were performed to estimate mean costs, QALYs, response rate, incremental cost-effectiveness ratios (ICERs), and associated uncertainty. Additional sensitivity analyses were done with imputed data, without extreme cost outliers, using the per protocol sample, and from a health care perspective.

Results In the ITT sample, societal costs were $€ 3572$ for MBCT + TAU $(n=47 ; 95 \%$ CI 2416 to 4995$)$ and $€ 3389$ for TAU ( $n=$ 49; 2327 to 4763). Average QALYs were 0.542 (0.522 to 0.563) per patient for MBCT + TAU and 0.534 (0.511 to 0.556) for TAU. In MBCT + TAU, more patients responded than in TAU (31\% versus 6\%; $M$ bootstrapped difference $25 \%, 12$ to $40 \%$ ). ICERs were $€ 21,963$ per QALY gained and $€ 389$ per responder. At a threshold of $€ 30,000$ per QALY, the probability of MBCT being cost-effective was $51 \%$. All sensitivity analyses showed more favorable results for MBCT + TAU.

Conclusions In most analyses, MBCT was found to be more costly and effective, particularly in terms of disease-specific outcome, than TAU. If the threshold exceeds $€ 30,000$ per QALY and $€ 1000$ per responder, MBCT seemed cost-effective in treating adult ADHD.
\end{abstract}

Keywords Adult ADHD $\cdot$ Mindfulness-based cognitive therapy $\cdot$ Cost-effectiveness $\cdot$ Health economy $\cdot$ Quality of life

Attention-deficit hyperactivity disorder (ADHD) is a neurodevelopmental disorder with an estimated prevalence of $2.5 \%$ at adult age (Simon et al. 2009). Its core symptoms affect academic, professional, and social functioning (Karlsdotter et al. 2016), and have a considerable personal and economic impact.

A systematic review of Doshi et al. (2012) showed that in the USA, the estimates of overall annual incremental (excess)

Lotte Janssen

Lotte.Janssen@Radboudumc.nl

1 Department of Psychiatry, Radboud University Medical Centre, P.O. Box 9101, (internal post 966) 6500

HB Nijmegen, The Netherlands

2 Department for Health Evidence, Radboud University Medical Centre, Nijmegen, The Netherlands

3 Reinier van Arkel, 's-Hertogenbosch, The Netherlands costs associated with adult ADHD ranged from \$105 to 194 billion. These overall societal costs, including costs for health care as well as productivity loss, were found to be almost three times higher for adults than for children and adolescents with ADHD. Workforce productivity and income loss (\$87 to 138 billion) was the largest contributor to the economic burden and accounted for 71 to $83 \%$ of the overall adult ADHD costs. ADHD was found to be associated with an additional 22 days

4 Centre for Developmental Disorders, Dimence, Deventer, The Netherlands

5 Department of Cognitive Neuroscience, Donders Institute for Brain, Cognition, and Behaviour, Radboud university medical centre, Nijmegen, The Netherlands

6 Karakter Child and Adolescent Psychiatry, Nijmegen, The Netherlands 
of lost role performance per year, including both absenteeism and presenteeism (de Graaf et al. 2008). The estimates of overall annual incremental health care costs associated with adult ADHD ranged from $\$ 16$ to 50 billion (Doshi et al. 2012). Comorbid psychiatric disorders, such as depression and anxiety disorders (Hodgkins et al. 2011; Karlsdotter et al. 2016), and risky behavior leading to traffic accidents (Bernfort et al. 2008) appeared to be more prevalent among ADHD patients, resulting in higher medical costs.

Evidently, effective interventions are needed in order to reduce functional impairments in adults with ADHD. In particular, those that are cost-effective and thus not only increase the health benefits but also offer value for money. Although pharmacotherapy with stimulants has proven to be effective in the short term (Faraone and Glatt 2010; Moriyama et al. 2013), current guidelines emphasize that drug treatment should be part of a multimodal treatment (Kooij et al. 2010; National Institute for Health and Care Excellence [NICE] 2018; Nederlandse Vereniging voor Psychiatrie [NVvP] 2015). Only one study conducted an economic evaluation of pharmacotherapy in adults with ADHD (Shah et al. 2017) and no studies to date have conducted an economic evaluation of additional psychosocial treatment options in an adult ADHD population.

Growing evidence suggests that a mindfulness-based intervention (MBI) might be a valuable additional treatment option for adult ADHD patients (Bachmann et al. 2016; Cairncross and Miller 2016; Hepark et al. 2015; Househam and Solanto 2016). Considered from an economic perspective, an advantage of an MBI is that it can be offered in a group format. A recent systematic review of the literature on the economic evaluation of third-wave CBT for the management of different physical and mental health conditions provided some evidence that mindfulness-based cognitive therapy (MBCT) is efficient from a societal or a third-party payer perspective (Feliu-Soler et al. 2018). However, these findings are inconclusive as some trials gave very positive results (Bogosian et al. 2015; Shawyer et al. 2016), while others gave only modest results (Kuyken et al. 2015; van Ravesteijn et al. 2013). A recent multicenter, single-blind, randomized controlled trial (RCT) has demonstrated that mindfulness-based cognitive therapy (MBCT) is effective in reducing clinicianrated core symptoms $(d=0.41)$ in adults with ADHD compared to treatment as usual (TAU), an effect which was maintained at 6-month follow-up $(d=0.43)$. More patients in the MBCT + TAU group $(31 \%)$ than in TAU $(5 \%)$ showed a clinical reliable improvement of ADHD symptoms (Janssen et al. 2018). However, it is unknown to what extent these clinical benefits in symptomatology outweigh the costs from a societal perspective, including health care costs and costs for productivity loss, and a health care perspective, including only medical costs. In the Netherlands, as in other countries, policy-makers are faced with limited healthcare budgets and need to choose among different treatment alternatives. Economic evaluation informs these policy-makers whether MBCT offers value for money in adults with ADHD. Thus, the aim of the current study is to conduct an economic evaluation of MBCT in addition to treatment as usual (TAU) in adult patients with ADHD alongside a Dutch multicenter RCT.

\section{Method}

\section{Participants}

Adult ADHD patients (over 18 years) were referred by three specialized outpatient clinics in the Netherlands and by selfselection. Patients were eligible when they fulfilled the criteria of a primary DSM-IV diagnosis of ADHD assessed with the diagnostic interview for ADHD in adults (DIVA; Kooij 2010). Exclusion criteria were as follows: (a) not capable of fillingout questionnaires in Dutch, (b) depressive disorder with psychotic symptoms or suicidality, (c) current manic episode, (d) borderline or antisocial personality disorder assessed with the screening list of the clinical interview for DSM-IV axis II disorders (SCID-II) (First and Gibbon 2004), (e) substance dependence, (f) autism spectrum disorder, (g) tic disorder with vocal tics, (h) learning difficulties or other cognitive impairments, and (i) former participation in MBCT or other MBI course or workshop ( $>2 \mathrm{~h}$ ). A psychiatric structured diagnostic interview (MINI-Plus; Van Vliet and De Beurs 2007) was used to assess criteria $\mathrm{b}, \mathrm{c}$, and $\mathrm{e}$.

Complete data for $96(80 \%)$ of the 120 patients (MBCT + TAU: $n=47$; TAU: $n=49$ ) were obtained (Fig. 1 ). The only difference between patients who did and patients who did not fill-out the questionnaires at $\mathrm{T} 1, \mathrm{~T} 2$, and/or $\mathrm{T} 3$ is that noncompleters were younger $(M=33, \mathrm{SD}=6.5)$ than completers $(M=41, \mathrm{SD}=10.8, p<.001)$. Baseline characteristics between the MBCT + TAU and TAU are summarized in Table 1. Patients in MBCT + TAU were more likely to work as an entrepreneur than in TAU. No significant differences were found in health care costs in the preceding 3 months (at T0), $M$ bootstrapped difference is $€-31$ (95\% CI -294 to 235 ), and productivity costs, $M$ bootstrapped difference is $€-419$ ( -1375 to 686 ).

\section{Procedure}

Trial Design This economic evaluation was conducted alongside a Dutch multicenter, single-blind, parallel-group, randomized controlled superiority trial on the efficacy of MBCT + TAU (active control group) versus TAU alone (passive control group; allocation ratio 1:1) in adults with ADHD. For more methodological details, see the published protocol (Janssen et al. 2015). The study had a time horizon of 


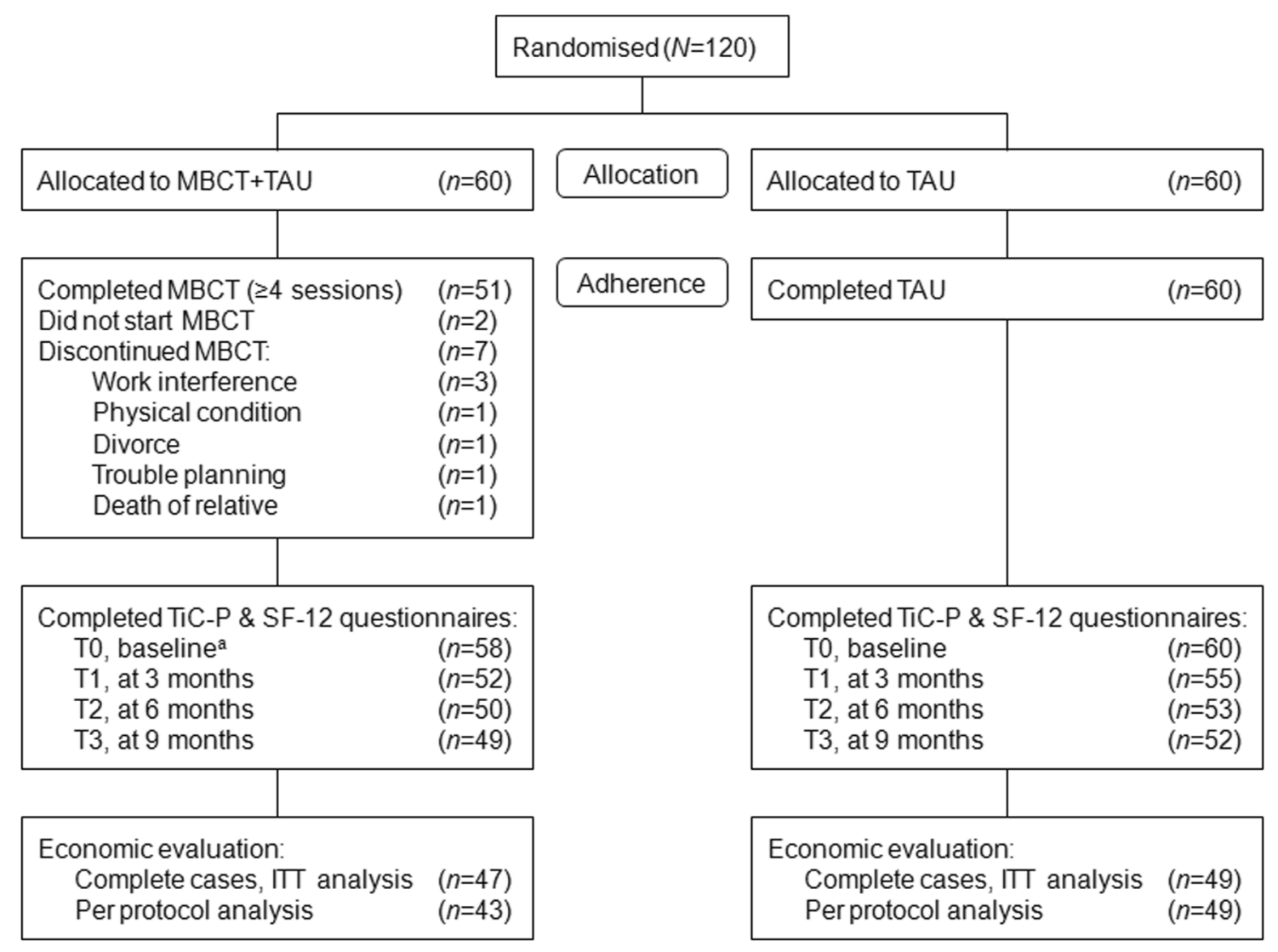

a. Although participants were randomised before filling-out T0, they were informed about allocation after completing TO.

Fig. 1 CONSORT flow diagram. MBCT, mindfulness-based cognitive therapy; TAU, treatment as usual; TiC-P, Trimbos/iMTA questionnaire for costs associated with psychiatric illness; SF-12, medical outcomes study 12-item short-form health survey; ITT, intention-to-treat

9 months, from baseline till 6-months follow-up after posttreatment (Janssen et al. 2018).

Intervention Patients in the MBCT + TAU group received, in addition to treatment as usual, an 8-week MBCT program (Segal et al. 2012) of $2.5 \mathrm{~h}$ per session and a 6-h silent day (Janssen et al. 2015). This program was offered after the baseline assessments. Patients were instructed to practice at home 6 days a week for about 30 min per day with audio-guided exercises. MBCT was taught in groups with approximately nine patients per group by four different mindfulness teachers, who all met the advanced criteria of the internationally agreed good practice guidelines of the UK Network for mindfulnessbased teachers (http://mindfulnessteachersuk.org.uk/pdf/ teacher-guidelines-2015.pdf). The competence levels of the four teachers were advanced (taught nine participants), competent (taught 21 participants), advanced beginner (taught 22 participants) and beginner (taught six participants) (Janssen et al. 2018) based on the mindfulnessbased interventions-teaching assessment criteria (MBI: TAC; Crane et al. 2012).

Patients in the TAU condition received the usual treatments for adult ADHD, consisting of pharmacotherapy and/or psychosocial treatments such as psychoeducation and skills training, except MBIs (Janssen et al. 2018). Patients were free to start, continue, and stop a treatment as desired. TAU was monitored during the study period. For a precise description of the received TAU in the period T0 to T1, see the RCT paper (Janssen et al. 2018).

\section{Measures}

The Trimbos/iMTA questionnaire for costs associated with psychiatric illness (TiC-P) (Bouwmans and Hakkaart-van Roijen 2013) was used to collect information on health care and societal costs. Patients were asked to fill out this online questionnaire at baseline (T0), and at 3 (T1), 6 (T2), and 9 (T3) months after baseline assessment. This self-report instrument consists of information on health care consumption including mental and general health care and medication as well as productivity loss in paid or unpaid work due to illness. The recall period for the TiC-P is 3 months for health care consumption and 1 month for productivity loss. To equalize the time period for health care and productivity costs, the costs for productivity loss over 1 month were extrapolated to the remaining 2 months. Previous research showed that the TiC-P is 
Table 1 Baseline characteristics of 96 study participants

\begin{tabular}{|c|c|c|c|c|c|}
\hline & \multicolumn{2}{|c|}{$\mathrm{MBCT}+\mathrm{TAU}(n=47)$} & \multicolumn{2}{|c|}{ TAU $(n=49)$} & \multirow[b]{2}{*}{$p^{\mathrm{a}}$} \\
\hline & $n$ & $\%$ & $n$ & $\%$ & \\
\hline Female gender & 24 & 51 & 23 & 47 & .686 \\
\hline Age; $M(\mathrm{SD})$ & 41.3 & 11.4 & 40.7 & 10.2 & $.807^{\mathrm{b}}$ \\
\hline Civil class ${ }^{\mathrm{c}}$ & & & & & .639 \\
\hline Married/living together & 24 & 52 & 30 & 61 & \\
\hline Unmarried/single & 14 & 30 & 14 & 29 & \\
\hline Divorced & 7 & 15 & 5 & 10 & \\
\hline Widowed & 1 & 2 & 0 & 0 & \\
\hline Employment status ${ }^{\mathrm{c}}$ & & & & & .036 \\
\hline Student & 5 & 11 & 2 & 4 & \\
\hline Wage labor & 18 & 39 & 23 & 47 & \\
\hline Entrepreneur & 10 & 22 & 2 & 4 & \\
\hline Housewife/man & 1 & 2 & 4 & 8 & \\
\hline Unemployed & 7 & 15 & 8 & 16 & \\
\hline (Partially) disabled & 4 & 9 & 10 & 20 & \\
\hline Elderly pension & 1 & 2 & 0 & 0 & \\
\hline Educational level $^{\mathrm{c}}$ & & & & & .123 \\
\hline Low & 7 & 15 & 3 & 6 & \\
\hline Middle & 15 & 33 & 25 & 51 & \\
\hline High & 24 & 52 & 21 & 43 & \\
\hline
\end{tabular}

${ }^{\text {a }}$ Chi-square test

${ }^{\mathrm{b}}$ Independent samples $t$ test

${ }^{\mathrm{c}}$ Baseline questionnaires were filled out by $n=46$ participants in the MBCT + TAU group

a feasible and reliable instrument for collecting data on medical consumption and productivity loss in patients with mild to moderate mental health problems (Bouwmans et al. 2013).

For the health care costs, standardized Dutch unit costs (Hakkaart-van Roijen et al. 2015) were used. When prices were not available, market prices were used. Additional treatment costs were $€ 445$ per person for patients who participated in the MBCT group, based on the applied price of the Radboudumc Center for Mindfulness. Medication costs were retrieved from the Dutch national tariff list accessed from July till September 2016 (Zorginstituut Nederland [ZIN] 2016). Medication costs that could not be retrieved from this website (e.g., vitamin pills) were excluded.

For the productivity costs, productivity loss in paid work was calculated according to the friction cost method: the number of hours patients were absent from their job multiplied by the actual gross wage per hour (Hakkaartvan Roijen et al. 2015). Only absenteeism was considered and the cause of absence was not taken into account. The friction period was defined as the period needed to replace the ill worker and to restore the initial production level. After this period, productivity costs fall back to zero. Following the Dutch manual for costing in economic evaluations (Hakkaart-van Roijen et al. 2015), a friction period of 85 days was used. Productivity loss in unpaid work was measured by multiplying the hours others took over unpaid labor tasks of the patient due to illness by the costs (Hakkaart-van Roijen et al. 2015).
Dutch price indices were used to update health care and productivity costs to the 2015 price level (Centraal Bureau voor de Statistiek [CBS] 2016). Costs were presented in Euros (the exchange rate with the US dollar was 1.11 in 2015).

Effectiveness was expressed in two ways: (1) with a generic measure of health benefit expressed in quality adjusted life years (QALY $=1$ year of life in optimal health), assessed with the medical outcomes study 12-item short-form health survey (SF-12; Ware et al. 1996), and (2) with a disease-specific measure of treatment response based on the DSM-IV symptom score of the screening version of the Conners' adult ADHD rating scale (CAARS-INV: SV; Adler et al. 2007).

Both outcome measures were assessed at T0, T1, T2, and T3. The SF-12 was reported online by the patients. The SF-12 scores were converted to the SF-6D, which is a 6-dimensional health state classification derived from a selection of SF-36 items (McHorney et al. 1993). At each time point, the six health states of the SF-6D were converted in utility values by assigning average preference weights derived from a general UK population of adults (Brazier et al. 2002). From these utility scores QALYs were calculated for each patient using the area under the curve (AUC) method combined with the last observation carried forward (LOCF) technique in case of one missing utility value. In addition, difference scores in utilities between T1/T2/T3 and baseline were calculated.

The CAARS-INV was rated by a blinded clinician to assess ADHD symptoms. Ratings were organized in DSM-IV symptom scores and these scores were converted in binomial variables (improved/unimproved) based on the reliable change index (RCI) of Jacobson and Truax (1991) to determine which patients responded to the treatment between baseline and $\mathrm{T} 1$. This time interval was similar to the used interval in the RCT (Janssen et al. 2018). Patients were considered improved when the RCI was smaller than -1.96 .

\section{Data Analyses}

Economic evaluations with generic and disease-specific effect measures were done on complete cases, i.e., all patients who filled-out the TiC-P and SF-12 or CAARS-INV at T1, T2, and T3. The base case analyses were performed from the societal perspective, including health care costs and costs for productivity loss, within the intention-to-treat (ITT) sample. Additionally, these analyses were replicated in the per protocol (PP) sample, consisting of only those patients who completed the originally allocated treatment (MBCT + TAU: patients who attended $\geq 4$ MBCT sessions; TAU: patients who did not attend an MBI). Total costs were based on adding up the health care and productivity loss costs for $\mathrm{T} 1, \mathrm{~T} 2$, and $\mathrm{T} 3$, reaching a time horizon of 9 months. The mean health care costs per person were compared between the two groups. Mean costs for health care and productivity loss were compared between groups at $\mathrm{T} 0$ to check for baseline differences. 
Bootstrap simulations with 1000 replications were performed, since cost data are generally highly skewed. Mean costs, QALYs, and response rate per treatment arm were calculated from the bootstrap replications, as well as $95 \%$ confidence intervals using the percentile method. The replications were graphed on a cost-effectiveness plane. The horizontal axis of this plane represents the incremental effects and the vertical axis represents the incremental costs. Each quadrant in the plane has a different implication for decision-making. If the majority of the cost-effectiveness pairs is located in the northwest quadrant, this would indicate that MBCT is more costly and less effective than TAU (MBCT is dominated). However, if the majority of the cost-effectiveness pairs is located in the southeast quadrant, this would indicate that MBCT is less costly and more effective than TAU (MBCT dominates). If the majority of the cost-effectiveness pairs is located in the other two quadrants, the cost-effectiveness of MBCT depends on the societal willingness to pay (WTP) for the gain of one extra unit of effect (QALY or responder), or the willingness to accept for a loss in effect. In this case, an incremental cost-effectiveness ratio (ICER) is calculated by dividing the incremental costs of MBCT by the incremental effects, which gives an estimate of the extra costs that are needed to gain one QALY/responder, or, if it is less costly and less effective, the savings per lost QALY/responder. A costeffectiveness acceptability curve (CEAC) is constructed showing the probability that the found ICER is acceptable for a range of monetary values that society might consider as the maximum WTP for a gain of one extra unit of effect. For the analyses with a generic effect measure, threshold values of $€ 30,000$ (NICE 2013) and $€ 80,000$ (ZIN 2015) per QALY were reported.

Secondary analyses with generic and disease-specific effect measures were performed from a health care perspective, with only medical costs included. Additionally, some sensitivity analyses for the analysis with a generic effect measure from a societal perspective in the ITT sample were conducted to assess the robustness of the results. At first, missing data were imputed according to LOCF and multiple imputation (MI) techniques. For MI, five datasets were created and these data were combined to produce estimates of the costs and QALYs. Secondly, an analysis without extreme cost outliers due to a physical, not ADHD-related problem was done.

\section{Results}

\section{Effectiveness}

Generic Mean difference scores in utilities based on the SF-6D between $\mathrm{T} 1$ and baseline were $0.026,(-0.008$ to 0.060$)$, for $\mathrm{MBCT}+\mathrm{TAU}$ and $0.003,(-0.028$ to 0.034$)$, for TAU
(Fig. 2). Difference scores increased the next 3 months in both groups. However, in the last 3 months these scores further increased in TAU, but decreased in MBCT + TAU. Average QALYs over the 9-month period were 0.542 per patient for $\mathrm{MBCT}+\mathrm{TAU}(0.522$ to 0.563$)$ and 0.534 for TAU ( 0.511 to $0.556)$, see Table 3 .

Disease-Specific In MBCT + TAU, 14 (31\%; 18 to $44 \%)$ patients responded to treatment and in TAU $3(6 \% ; 0$ to $14 \%)$, resulting in a bootstrapped difference between groups of $25 \%$ (12 to $40 \%$ ), implying that patients in MBCT + TAU responded better to the treatment than in TAU (Table 3).

\section{Costs}

The bootstrapped total costs between MBCT + TAU ( $€ 3572$; 2416 to 4995$)$ and TAU ( $€ 3389 ; 2327$ to 4763$)$ were similar in the ITT sample (Table 2). Health care costs for MBCT + TAU were $€ 631$ ( 25 to 1262 ) higher than for TAU. This was primarily due to intervention costs. Furthermore, patients in MBCT+TAU had higher ADHD medication costs than patients in TAU. The majority of all participants had contact with their general practitioner, received mental health care, and used ADHD medication. The bootstrapped productivity costs for MBCT + TAU were $€ 1502$, (614 to 2680) and for TAU $€ 1989$, (1074 to 3074).

\section{Economic Evaluation}

Generic Dividing the difference in bootstrapped societal costs $(€ 183)$ by the difference in bootstrapped QALYs $(0.008)$ resulted in an ICER of $€ 21,963$ per QALY gained (Table 3). The

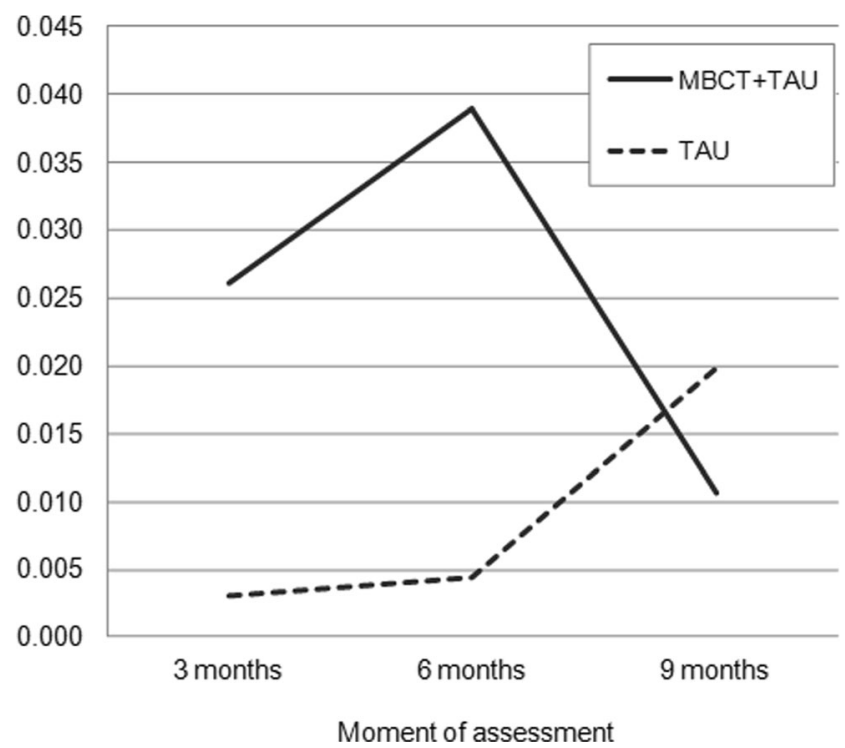

Fig. 2 Difference scores in mean utilities between T1, T2, T3, and baseline on the SF-6D for MBCT + TAU and TAU. MBCT, mindfulness-based cognitive therapy; TAU, treatment as usual 
Table 2 Total and bootstrapped mean costs (in Euros) for (sub) totals per condition for complete cases in the ITT sample over 9 months

\begin{tabular}{|c|c|c|c|c|c|c|}
\hline & \multicolumn{2}{|c|}{$\mathrm{MBCT}+\mathrm{TAU}(n=47)$} & \multicolumn{2}{|l|}{ TAU $(n=49)$} & \multirow[t]{2}{*}{ Incremental costs } & \multirow[t]{2}{*}{$95 \% \mathrm{CI}$} \\
\hline & $\%$ of patients & $M$ costs per person & $\%$ of patients & $M$ costs per person & & \\
\hline \multicolumn{7}{|l|}{ Health care costs ${ }^{\mathrm{a}}$} \\
\hline Primary care ${ }^{\mathrm{b}}$ & 85 & 128 & 76 & 100 & 27 & $-24,82$ \\
\hline Hospital care ${ }^{c}$ & 30 & 223 & 33 & 122 & 101 & $-50,310$ \\
\hline Paramedical care $^{\mathrm{d}}$ & 57 & 226 & 53 & 170 & 56 & $-77,191$ \\
\hline Mental healthcare & 77 & 773 & 67 & 770 & 3 & $-403,416$ \\
\hline Occupational health care ${ }^{f}$ & 11 & 22 & 20 & 38 & -16 & $-51,20$ \\
\hline Alternative healers ${ }^{\mathrm{g}}$ & 9 & 46 & 10 & 32 & 14 & $-41,72$ \\
\hline ADHD medication & 74 & 122 & 61 & 71 & $51 *$ & 2,102 \\
\hline Other medication & 46 & 27 & 57 & 72 & -44 & $-94,2$ \\
\hline MBCT & 98 & 436 & 0 & 0 & & \\
\hline Bootstrapped subtotal health care costs & & 1997 & & 1366 & $631 *$ & 25,1262 \\
\hline \multicolumn{7}{|l|}{ Costs of lost productivity ${ }^{\mathrm{a}}$} \\
\hline Absent from paid work & & 1162 & & 1628 & -466 & $-1945,1103$ \\
\hline Replacement of unpaid work & & 335 & & 386 & -51 & $-386,276$ \\
\hline Bootstrapped subtotal productivity loss & & 1502 & & 1989 & -487 & $-1926,1071$ \\
\hline Bootstrapped total costs & & 3572 & & 3389 & 183 & $-1635,2008$ \\
\hline
\end{tabular}

${ }^{a}$ The means of the subcategories are based on individual bootstrap analyses and therefore do not sum up to the subtotals

${ }^{\mathrm{b}}$ Contact with general practitioner

${ }^{\mathrm{c}}$ Outpatient contact with medical specialist, day treatment and inpatient treatment for medical, psychiatric, residential, and rehabilitation care, emergency treatment

${ }^{\mathrm{d}}$ Contact with physiotherapist, occupational therapist, speech therapist, dietician, social worker, home caregiver

${ }^{\mathrm{e}}$ Contact with psychologist, psychiatrist, psychotherapist, visits within the mental health care, addiction treatment, support group

${ }^{\mathrm{f}}$ Contact with company physician

${ }^{\mathrm{g}}$ Contact with homeopath, acupuncturist

$*$ Statistically significant difference for $p<.05$

cost-effectiveness plane (Fig. 3) revealed that the costeffective pairs were located in all quadrants. Most pairs (36\%) were located in the north-east quadrant, where MBCT is more effective but also more costly than TAU. The CEAC indicated that the probability of MBCT being cost-effective is 51 and $60 \%$ if society is willing to pay $€ 30,000$ and $€ 80,000$ for one gained QALY, respectively (Fig. 4). Additional PP analysis showed that MBCT + TAU was $€ 261$ less costly than TAU and resulted in a QALY gain of 0.011 , implying that MBCT dominated TAU.

Disease-Specific Dividing the difference in bootstrapped societal costs $(€ 98)$ by the difference in the bootstrapped response rate $(25 \%)$ resulted in an ICER of $€ 389$ per responder gained (Table 3). The CEAC indicated that if the societal WTP is below $€ 1000$, the probability of MBCT being cost-effective is $46 \%$, whereas this probability increased to $\geq 88 \%$ if the societal WTP is $\geq € 5000$ (Fig. 5). Additional PP analysis showed that MBCT was $€ 238$ less costly than TAU with a responder gain of $24 \%$, resulting in MBCT dominating TAU.

\section{Secondary Analyses}

\section{Health Care Perspective}

Generic ITT analysis showed that MBCT + TAU was $€ 631$ more costly than TAU and resulted in a QALY gain of 0.008 and an ICER of $€ 75,581$. The ICER dropped to $€ 50,390$ in the PP analysis. MBCT + TAU stayed $€ 581$ more costly than TAU and resulted in a slightly higher QALY gain of 0.012 .

Disease-Specific ITT analysis demonstrated a difference in bootstrapped health care costs of $€ 600$ with a responder gain of $25 \%$, implying that MBCT is more effective but also more costly than TAU. The corresponding ICER was $€ 2405$ (Table 3). PP analysis showed a comparable result.

\section{Sensitivity Analyses}

Replication of the base case analyses with a generic effect measure with imputation based on LOCF showed that 
MBCT + TAU was $€ 469$ less costly than TAU and yielding 0.001 more QALYs, resulting in MBCT dominating TAU. Replication of the analyses with imputed data based on MI showed a difference in bootstrapped costs of $€ 109$ with a difference in bootstrapped QALYs of 0.004, resulting in a slightly higher ICER of $€ 28,632$. Analysis without extreme cost outliers (MBCT + TAU: $n=2$, cancer and arthrosis; TAU: $n=1$, broken foot, bruised ankle and tailbone) demonstrated that MBCT + TAU was €227 less costly combined with a QALY gain of 0.008 , resulting in MBCT dominating TAU.

\section{Discussion}

This study showed that societal costs and effects expressed in a generic measure were slightly higher for MBCT + TAU compared to TAU, resulting in an ICER of $€ 21,963$ per QALY. Replications of this analysis in the treatment adherent sample and the majority of the sensitivity analyses, revealed a more straightforward scenario in which MBCT dominated TAU. When the effects were expressed in a disease-specific measure, patients in MBCT + TAU responded better to the treatment than in TAU, resulting in an ICER of $€ 389$ per responder in the ITT sample and in MBCT dominating TAU in the PP sample.

When observing the costs for health care and productivity loss separately, health care costs appeared to be higher for MBCT + TAU than for TAU while costs for lost productivity were not statistically significantly different. Nevertheless, the difference between groups in lost productivity costs was quite large, favoring MBCT + TAU. Apparently, productivity costs had an equalizing effect on the cost differences between groups, resulting in substantially higher ICERs from a health care perspective in comparison to the societal perspective.

An interesting finding was the cost difference between groups for ADHD medication, with higher costs in the MBCT group. This cost difference increased over time. However, the percentages of patients on ADHD drugs increased in both groups over time (MBCT + TAU, 70 to $74 \%$; TAU, 57 to $61 \%$ ). Perhaps, participation in MBCT improved general medication adherence due to reasons such as a greater awareness of impairments and decreased forgetfulness.

\section{Limitations and Future Research}

Methodological strengths of the study are the use of an ecologically valid design which stayed close to the daily clinical practice of adult ADHD (Janssen et al. 2018), the use of the validated generic measure SF-12 to calculate QALYs, the combination of generic and disease-specific analyses which addresses the specific impairments associated with ADHD, and the inclusion of 
Fig. 3 Cost-effectiveness plane showing 1000 bootstrap replications of costs (in Euros) and effects (QALY) for MBCT + TAU and TAU from a societal perspective in the ITT-sample. QALY, quality adjusted life years

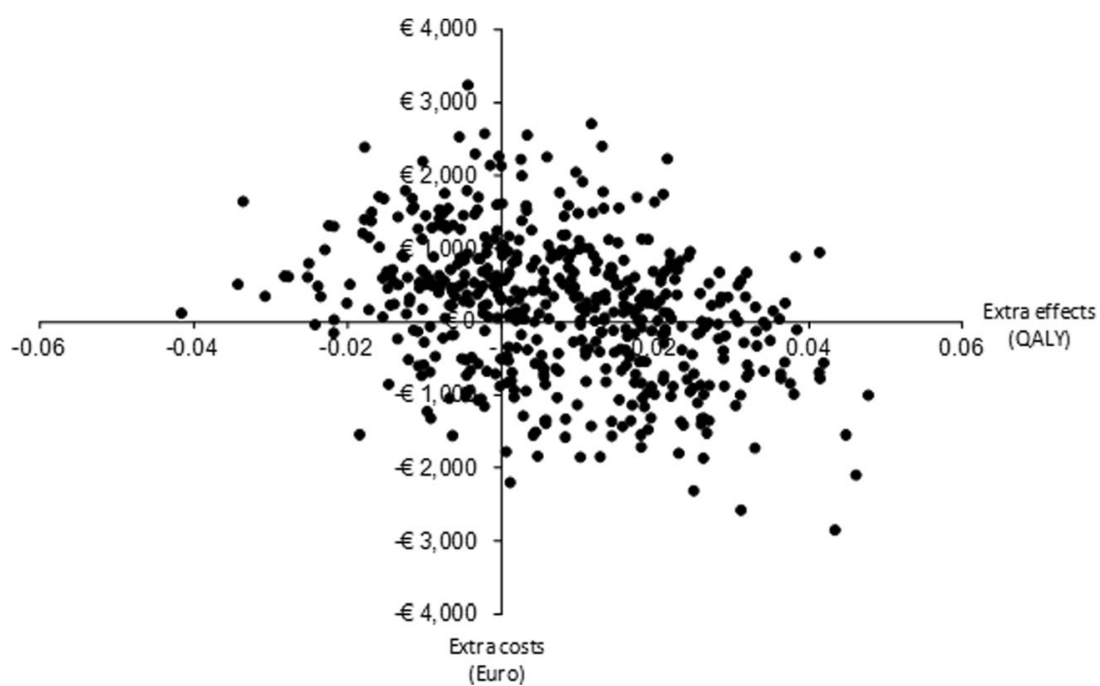

productivity costs next to health care costs. The inclusion of productivity costs is highly relevant since previous research showed that ADHD had a significant impact in the workplace (Doshi et al. 2012; Hodgkins et al. 2011).

A limitation of this study is that only productivity costs for absenteeism and not for presenteeism were included in the analyses. Previous studies showed that the majority of productivity loss in adult ADHD is associated with reduced efficiency rather than sickness absence (Kessler et al. 2005, 2009). However, costs for productivity loss emerging from presenteeism were not included, because of methodological difficulties in measuring and valuing efficiency loss (Bouwmans et al. 2013). It is likely that this choice led to an underestimation of the cost-effectiveness and resulted in more conservative findings, since there is evidence that $\mathrm{MBCT}$ improves the efficiency of attentional functions (Malinowski 2013). A second limitation is that the data was exclusively based on self-report, which might have underestimated medication costs (Van den Brink et al. 2004). Although research demonstrated that the TiC-P is a reliable alternative for collecting data on resource use compared to data from registries (Bouwmans et al. 2013), this specific patient group perhaps had difficulty with recalling medical consumption and productivity loss due to forgetfulness. Another limitation is the amount of missing data of $20 \%$, which was handled with the sensitivity analyses based on LOCF and MI. Finally, although the difference in lost productivity costs at baseline was not significant, this difference was quite large. No adjustment was made for this imbalance, because this difference seemed random and therefore not predictive for costs during follow-
Fig. 4 Cost-effectiveness acceptability curves for costs per gained QALY. The curves indicate the probability ( $y$-axis) of MBCT + TAU being costeffective compared to TAU, given the threshold value ( $x$-axis) for a QALY. QALY, quality adjusted life years; ICER, incremental cost-effectiveness ratio

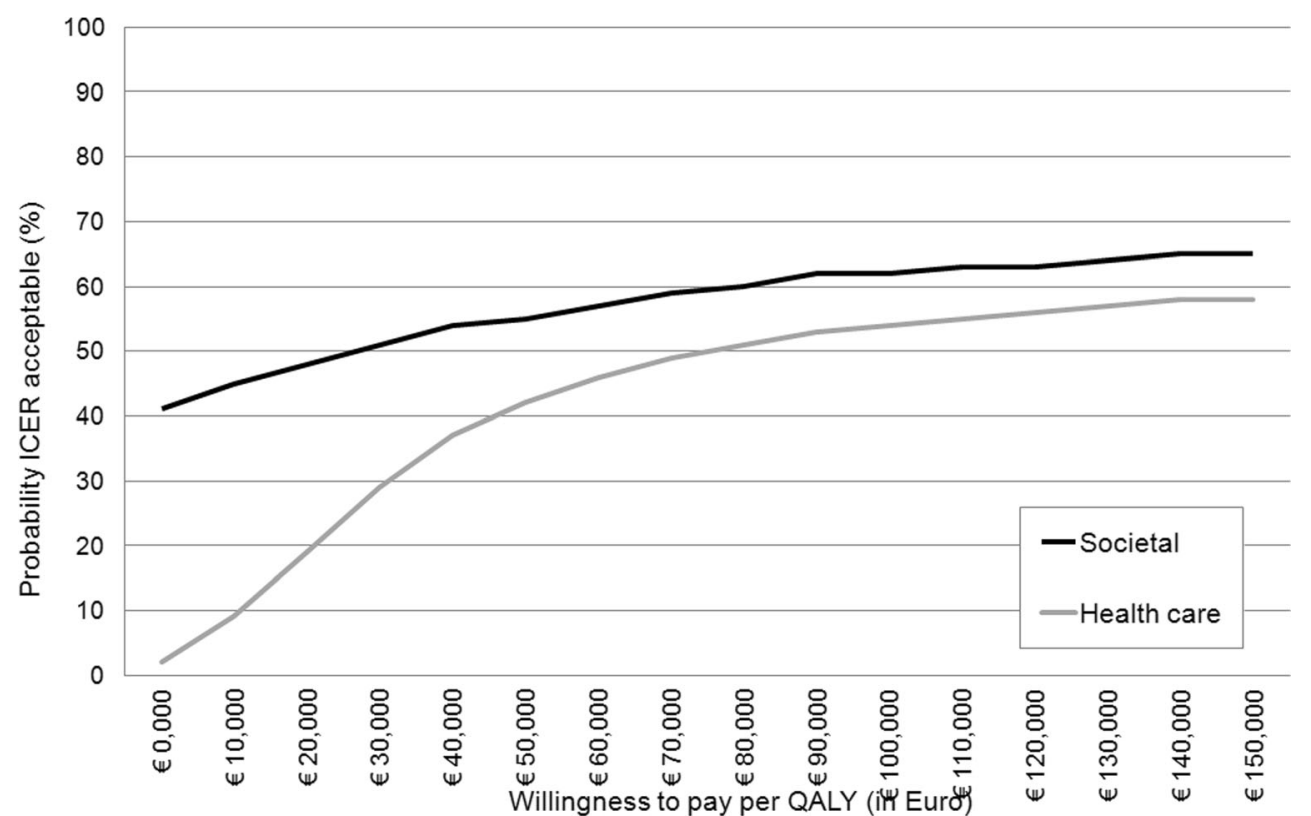


Fig. 5 Cost-effectiveness acceptability curves for costs per gained responder. The curves indicate the probability ( $y$-axis) of MBCT + TAU being costeffective compared to TAU, given the threshold value ( $x$-axis) for a responder. QALY, quality adjusted life years; ICER, incremental cost-effectiveness ratio

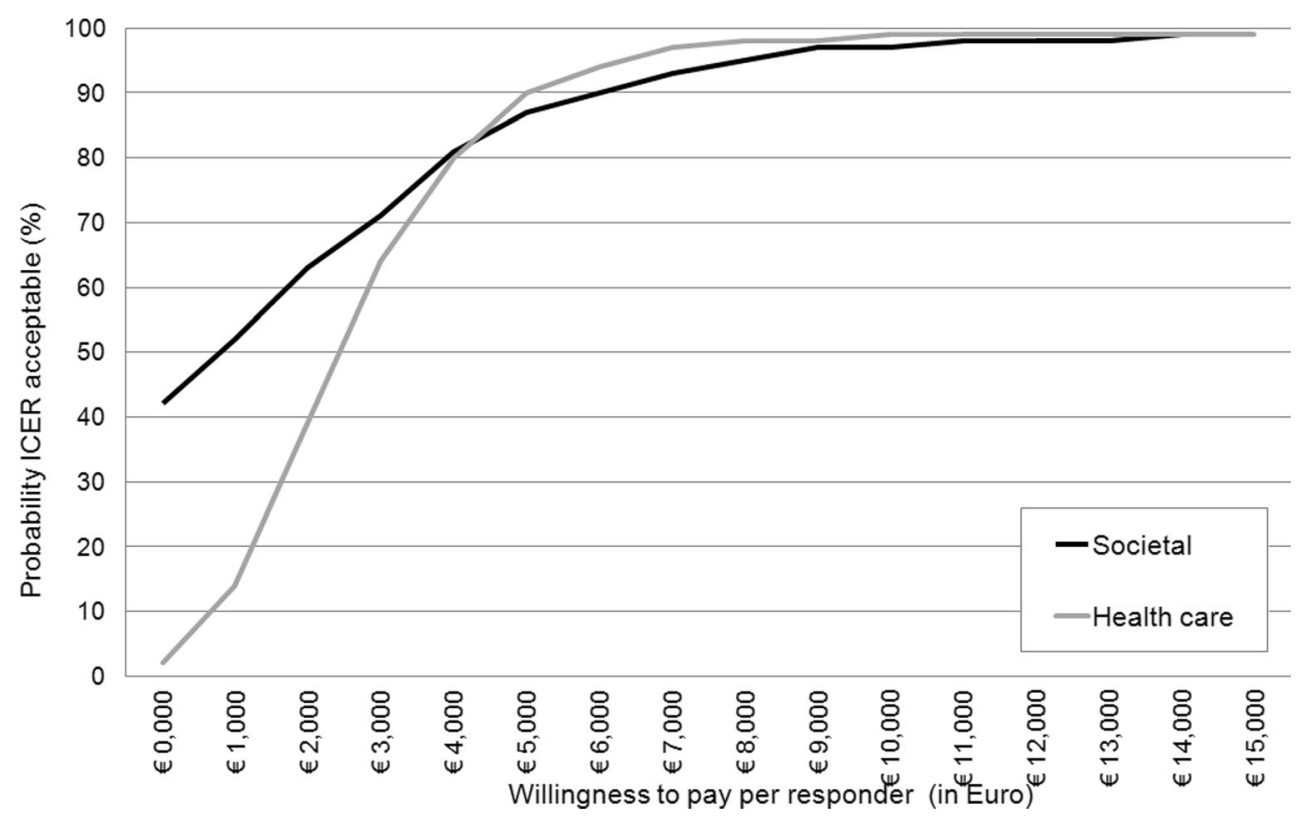

up, which is an important assumption when adjusting for baseline imbalances (Van Asselt et al. 2009).

In accordance with the Dutch guideline (Hakkaart-van Roijen et al. 2015), the friction cost method was used to estimate productivity loss in paid work. In each arm, one participant had been absent from work longer than the friction period. These participants were absent from work during the period between $\mathrm{T} 0$ and $\mathrm{T} 2$. Hence, in the human capital approach, the productivity costs for these participants were similar. This implies that by using the human capital approach, the total costs in each arm would increase, but the incremental costs would remain the same. Hence, use of the human capital approach would not impact the ICERs and conclusion of our study.

There is no (inter)national consensus regarding an acceptable cost-effectiveness threshold for health technologies. In the Netherlands, it is suggested that this value depends on the burden of disease with a ceiling of $€ 80,000$ per QALY in the case of maximum burden (ZIN 2015). The exact burden of disease for adult ADHD is unclear, but there is some empirical information about the burden over patients and society. Garcia et al. (2012) found an association between ADHD severity and negative life events in adults and Hinnenthal et al. (2005) found that the economic burden of adult ADHD was less than depression or diabetes, but greater than seasonal allergy. The National Institute for Clinical Excellence (NICE 2013 ) in the UK stated a threshold value of $£ 20,000$ to $£ 30,000$ (approximately $€ 22,000$ to $€ 34,000$ ) and North American studies usually use $\$ 50,000$ or $\$ 100,000$ (approximately $€ 42,000$ to $€ 84,000$ ) (Rudmik and Drummond 2013). When applying $€ 30,000$ as a threshold, the probability of MBCT being cost-effective is $51 \%$ (ITT) and $70 \%$ (PP) for the societal perspective.
The economic evaluation with a disease-specific effect measure (i.e., cost-effectiveness analysis) requires another threshold value than the economic evaluation with a generic effect measure (i.e., cost-utility analysis). By presenting the estimated ICERs together with the corresponding probabilities for a range of threshold values, decision makers were provided relevant information to make cost-effectiveness choices depending on their WTP for a responder gained. Whether these ICERs are acceptable depends for example on the consolidation of the treatment effects over time. A recent RCT showed that the improvements in ADHD symptoms were maintained until 6-month follow-up (Janssen et al. 2018), which is promising. Additionally, it is unclear whether the results of our trial-based economic evaluation are transferable to other countries. Treatment as usual and associated resource use may differ between countries, and also the effect of MBCT might depend on cultural aspects. Readers should carefully consider whether they expect our results to apply to their setting. Checklists exists to do this in a formal manner (Welte et al. 2004).

The finding that MBCT is especially cost-effective in patients who adhered to the treatment, implies that it is important to search for effective ways to increase the adherence, for instance by sending reminders for training sessions and actively contacting participants in case of no shows. A recent pilot study gave insight in perceived facilitators and barriers during MBCT which can, in some cases, be taken into account, such as offering a proper amount of directiveness by the teacher and stimulating helpful coping strategies (Janssen et al. 2017).

Future research might consider combining self-report with less subjective data sources such as patient records showing the medical health care history registered by a health care provider. A second recommendation is to make use of a time 
horizon longer than 9 months to improve the accuracy of the estimates. Furthermore, subgroup analyses are suggested on clinically relevant constructs to explore which ADHD patients benefit most of MBCT, for instance, patients with and without psychiatric comorbidity, since previous research showed that a substantial proportion of the total costs was related to the treatment of comorbidity such as depression (Birnbaum et al. 2005). A last recommendation is to develop a more responsive utility measure, since the SF-12 might be too generic to assess clinically relevant changes in ADHD patients. In this study, this restriction was handled by also expressing effectiveness in a disease-specific measure of treatment response.

Acknowledgements The authors thank all participants for their time and effort, the mindfulness teachers for teaching the MBCT groups, Irene Geujen for coordinating the data collection at Dimence, Geert Schattenberg for data management, and Caroline Truijens for her assistance in a MBCT group. We also thank the interviewers of the CAARS, the employees of the specialized outpatient clinics for ADHD, and the secretaries of the Reinier van Arkel Groep, Dimence, and Radboudumc for their contribution to this research project.

Author Contributions LJ, JG, CK, PC, BS, SH, JB, and AS contributed to the design of the study. AS was the principal investigator of the study. $\mathrm{LJ}, \mathrm{CK}, \mathrm{PC}, \mathrm{BS}$, and $\mathrm{SH}$ were involved in recruiting participants. LJ took care of the logistics of the project and data collection and MS collaborated in the data collection. LJ analyzed and interpreted the data under supervision of JG. LJ drafted the paper, which was critically modified and supplemented by all other authors. All authors read and approved the final version of the manuscript.

Funding This work was supported by ZonMW, the Netherlands Organization for Health Research and Development (Grant number 837001501, awarded to Prof. Dr. Speckens).

\section{Compliance with Ethical Standards}

Conflict of Interest The research team declares it had no part in developing the original MBCT program. AS, LJ, and SH made small modifications to this program as described in our pilot study (Janssen et al. 2017). The team does not gain income from the sale of books on MBCT, nor does it gain income from giving lectures or workshops about it. AS is the founder and clinical director of the Radboudumc Center for Mindfulness. LJ and MS are affiliated with this center. JB has been in the past 4 years as a consultant to/member of advisory board of/and/or speaker for Janssen Cilag BV, Eli Lilly, Lundbeck, Shire, Medice, and Servier. $\mathrm{He}$ is not an employee of any of these companies and not a stock shareholder of any of these companies. He has no other financial or material support, including expert testimony, patents, and royalties. CK has also been a member of the advisory board and consultancy team of Eli Lilly BV and was a speaker at the Adult-ADHD Academy of Eli Lilly. The other authors declare that they had no competing interests.

Ethical Approval The study protocol has been approved by the local medical ethics committee CMO Arnhem-Nijmegen for all participating centers (2014/206). All procedures contributing to this RCT comply with the ethical standards of the relevant national and institutional committees on human experimentation and with the Helsinki Declaration of 1975, as revised in 2008.
Informed Consent Informed consent was obtained from all individual participants included in the study.

Open Access This article is distributed under the terms of the Creative Commons Attribution 4.0 International License (http:// creativecommons.org/licenses/by/4.0/), which permits unrestricted use, distribution, and reproduction in any medium, provided you give appropriate credit to the original author(s) and the source, provide a link to the Creative Commons license, and indicate if changes were made.

\section{References}

Adler, L. A., Faraone, S. V., Spencer, T. J., Michelson, D., Reimherr, F. W., Glatt, S. J., et al. (2007). The reliability and validity of self and investigator ratings of ADHD in adults. Journal of Attention Disorders, 11(6), 711-719.

Bachmann, K., Lam, A. P., \& Philipsen, A. (2016). Mindfulness-based cognitive therapy and the adult ADHD brain: a neuropsychotherapeutic perspective. Frontiers in Psychiatry, 7(117). https://doi.org/10.3389/fpsyt.2016.00117.

Bernfort, L., Nordfeldt, S., \& Persson, J. (2008). ADHD from a socioeconomic perspective. Acta Paediatrica, 97(2), 239-245.

Birnbaum, H. G., Kessler, R. C., Lowe, S. W., Secnik, K., Greenberg, P. E., Leong, S. A., et al. (2005). Costs of attention deficithyperactivity disorder (ADHD) in the US: excess costs of persons with ADHD and their family members in 2000. Current Medical Research and Opinion, 21(2), 195-205.

Bogosian, A., Chadwick, P., Windgassen, S., Norton, S., McCrone, P., Mosweu, I., et al. (2015). Distress improves after mindfulness training for progressive MS: a pilot randomised trial. Multiple Sclerosis Journal, 21(9), 1184-1194.

Bouwmans, C., \& Hakkaart-van Roijen, L. (2013). TiC-P volwassenen: Vragenlijst over zorggebruik en productiviteitsverliezen bij psychische aandoeningen [TiC-P adults: Questionnaire about health consumption and productivity losses in psychiatric illness]. Rotterdam: Erasmus University.

Bouwmans, C., De Jong, K., Timman, R., Zijlstra-Vlasveld, M., Van der Feltz-Cornelis, C., Tan, S. S., et al. (2013). Feasibility, reliability and validity of a questionnaire on healthcare consumption and productivity loss in patients with a psychiatric disorder (TiC-P). BMC Health Services Research, 13(1), 217. https://doi.org/10.1186/ 1472-6963-13-217.

Brazier, J., Roberts, J., \& Deverill, M. (2002). The estimation of a preference-based measure of health from the SF-36. Journal of Health Economics, 21(2), 271-292.

Cairncross, M., \& Miller, C. J. (2016). The effectiveness of mindfulnessbased therapies for ADHD: a meta-analytic review. Journal of Attention Disorders, 1-17. https://doi.org/10.1177/ 1087054715625301.

Centraal Bureau voor de Statistiek (CBS) (2016). Consumentenprijzen; prijsindex $2006=100,1996-2015$. Retrieved from http://statline. cbs.nl/Statweb/publication/.

Crane, R. S., Kuyken, W., Williams, J. M. G., Hastings, R. P., Cooper, L., \& Fennell, M. J. (2012). Competence in teaching mindfulness-based courses: concepts, development and assessment. Mindfulness, 3(1), $76-84$.

de Graaf, R., Kessler, R. C., Fayyad, J., ten Have, M., Alonso, J., Angermeyer, M., et al. (2008). The prevalence and effects of adult attention-deficit/hyperactivity disorder (ADHD) on the performance of workers: results from the WHO world mental health survey initiative. Occupational and Environmental Medicine, 65(12), 835842.

Doshi, J. A., Hodgkins, P., Kahle, J., Sikirica, V., Cangelosi, M. J., Setyawan, J., et al. (2012). Economic impact of childhood and adult 
attention-deficit/hyperactivity disorder in the United States. Journal of the American Academy of Child and Adolescent Psychiatry, 51(10), 990-1002.

Faraone, S. V., \& Glatt, S. J. (2010). A comparison of the efficacy of medications for adult attention-deficit/hyperactivity disorder using meta-analysis of effect sizes. Journal of Clinical Psychiatry, 71(6), 754-763.

Feliu-Soler, A., Cebolla, A., McCracken, L. M., D’Amico, F., Knapp, M., López-Montoyo, A., et al. (2018). Economic impact of third-wave cognitive behavioral therapies: a systematic review and quality assessment of economic evaluations in randomized controlled trials. Behavior Therapy, 49(1), 124-147.

First, M. B., \& Gibbon, M. (2004). The structured clinical interview for DSM-IV Axis I disorders (SCID-I) and the structured clinical interview for DSM-IV Axis II disorders (SCID-II) Comprehensive handbook of psychological assessment, Vol. 2: Personality assessmen (pp. 134-143)t. Hoboken: Wiley.

Garcia, C., Bau, C., Silva, K., Callegari-Jacques, S., Salgado, C., Fischer, A., et al. (2012). The burdened life of adults with ADHD: Impairment beyond comorbidity. European Psychiatry, 27(5), 309-313.

Hakkaart-van Roijen, L., Van der Linden, N., Bouwmans, C., Kanters, T., \& Tan, S. S. (2015). Kostenhandleiding Methodologie van kostenonderzoek en referentieprijzen voor economische evaluaties in de gezondheidszorg. Geactualiseerde versie. [Dutch manual for costing in economic evaluations]. Diemen: Zorginstituut Nederland.

Hepark, S., Janssen, L., de Vries, A., Schoenberg, P. L. A., Donders, R., Kan, C. C., et al. (2015). The efficacy of adapted MBCT on core symptoms and executive functioning in adults with ADHD: a preliminary randomized controlled trial. Journal of Attention Disorders. https://doi.org/10.1177/1087054715613587.

Hinnenthal, J. A., Perwien, A. R., \& Sterling, K. L. (2005). A comparison of service use and costs among adults with ADHD and adults with other chronic diseases. Psychiatric Services, 56(12), 1593-1599.

Hodgkins, P., Montejano, L., Sasané, R., \& Huse, D. (2011). Cost of illness and comorbidities in adults diagnosed with attention-deficit/ hyperactivity disorder: a retrospective analysis. The Primary Care Companion CNS Disorders, 13(2). https://doi.org/10.4088/PCC. $10 \mathrm{~m} 01030$.

Househam, A. M., \& Solanto, M. V. (2016). Mindfulness as an intervention for ADHD. The ADHD Report, 24(2), 1-9.

Jacobson, N. S., \& Truax, P. (1991). Clinical significance: a statistical approach to defining meaningful change in psychotherapy research. Journal of Consulting and Clinical Psychology, 59(1), 12-19.

Janssen, L., Kan, C. C., Carpentier, P. J., Sizoo, B., Hepark, S., Grutters, J., et al. (2015). Mindfulness based cognitive therapy versus treatment as usual in adults with attention deficit hyperactivity disorder (ADHD). BMC Psychiatry, 15(1), 1-10. https://doi.org/10.1186/ s12888-015-0591-x.

Janssen, L., De Vries, A., Hepark, S., \& Speckens, A. E. (2017). The feasibility, effectiveness, and process of change of mindfulnessbased cognitive therapy for adults with ADHD: a mixed method pilot study. Journal of Attention Disorders. https://doi.org/10.1177/ 1087054717727350.

Janssen, L., Kan, C., Carpentier, P., Sizoo, B., Hepark, S., Schellekens, M., et al. (2018). Mindfulness-based cognitive therapy v. treatment as usual in adults with ADHD: a multicentre, single-blind, randomised controlled trial. Psychological Medicine, 49(1), 55-65.

Karlsdotter, K., Bushe, C., Hakkaart, L., Sobanski, E., Kan, C., Lebrec, J., et al. (2016). Burden of illness and health care resource utilization in adult psychiatric outpatients with attention-deficit/hyperactivity disorder in Europe. Current Medical Research and Opinion, 32(9), $1547-1556$

Kessler, R. C., Adler, L., Ames, M., Barkley, R. A., Birnbaum, H., Greenberg, P., et al. (2005). The prevalence and effects of adult attention deficit/hyperactivity disorder on work performance in a nationally representative sample of workers. Journal of Occupational and Environmental Medicine, 47(6), 565-572.

Kessler, R., Lane, M., Stang, P., \& Van Brunt, D. (2009). The prevalence and workplace costs of adult attention deficit hyperactivity disorder in a large manufacturing firm. Psychological Medicine, 39(1), 137147.

Kooij, J. J. S. (2010). Diagnostic interview for ADHD in adults 2.0 (DIVA 2.0) Adult ADHD: Diagnostic assessment and treatment. Amsterdam: Pearson Assessment and Information.

Kooij, J. J. S., Bejerot, S., Blackwell, A., Caci, H., Casas-Brugué, M., Carpentier, P. J., et al. (2010). European consensus statement on diagnosis and treatment of adult ADHD: the European Network Adult ADHD. BMC Psychiatry, 10(1), 67. https://doi.org/10.1186/ 1471-244x-10-67.

Kuyken, W., Hayes, R., Barrett, B., Byng, R., Dalgleish, T., Kessler, D., et al. (2015). Effectiveness and cost-effectiveness of mindfulnessbased cognitive therapy compared with maintenance antidepressant treatment in the prevention of depressive relapse or recurrence (PREVENT): a randomised controlled trial. The Lancet, 386(9988), 63-73.

Malinowski, P. (2013). Neural mechanisms of attentional control in mindfulness meditation. Frontiers in Neuroscience, 7(8). https://doi.org/ 10.3389/fnins.2013.00008.

McHorney, C. A., Ware, J. E., Jr., \& Raczek, A. E. (1993). The MOS 36item short-form health survey (SF-36): II. Psychometric and clinical tests of validity in measuring physical and mental health constructs. Medical Care, 31(3), 247-263.

Moriyama, T. S., Polanczyk, G. V., Terzi, F. S., Faria, K. M., \& Rohde, L. A. (2013). Psychopharmacology and psychotherapy for the treatment of adults with ADHD: a systematic review of available metaanalyses. CNS Spectrums, 18(6), 296-306.

National Institute for Health and Care Excellence (NICE). (2013). Judging whether public health interventions offer value for money. Retrieved from https://www.nice.org.uk/advice/lgb10/chapter/ judging-the-cost-effectiveness-of-public-health-activities.

National Institute for Health and Care Excellence (NICE). (2018). Attention deficit hyperactivity disorder: diagnosis and management of ADHD in children, young people and adults. Leicester, UK: British Psychological Society.

Nederlandse Vereniging voor Psychiatrie (NVvP). (2015). Richtlijn ADHD bij volwassenen: Fase 1 - diagnostiek en medicamenteuze behandeling [Guidelines ADHD in adults: Phase 1 - diagnostics and pharmacotherapy]. Retrieved from https://www.nvvp.net/website/ nieuws/2015/monodisciplinaire-richtlijn-adhd-bij-volwassenenfase-1-gepubliceerd.

Rudmik, L., \& Drummond, M. (2013). Health economic evaluation: important principles and methodology. Laryngoscope., 123(6), 13411347.

Segal, Z. V., Williams, J. M. G., \& Teasdale, J. D. (2012). Mindfulnessbased cognitive therapy for depression. New York: Guilford Press.

Shah, S., Wei, H., Jayawardhana, J., Perri, M., Cobran, E., \& Young, H. N. (2017). Cost-utility analysis of methylphenidate and amphetamine/dexamphetamine in adults with attention-deficit hyperactivity disorder. Journal of Pharmaceutical Health Services Research, 8(2), 101-106.

Shawyer, F., Enticott, J. C., Özmen, M., Inder, B., \& Meadows, G. N. (2016). Mindfulness-based cognitive therapy for recurrent major depression: a 'best buy' for health care? Australian and New Zealand Journal of Psychiatry, 50(10), 1001-1013.

Simon, V., Czobor, P., Balint, S., Meszaros, A., \& Bitter, I. (2009). Prevalence and correlates of adult attention-deficit hyperactivity disorder: meta-analysis. British Journal of Psychiatry, 194(3), 204 211.

Van Asselt, A. D., Van Mastrigt, G. A., Dirksen, C. D., Arntz, A., Severens, J. L., \& Kessels, A. G. (2009). How to deal with cost differences at baseline. Pharmacoeconomics., 27(6), 519-528. 
Van den Brink, M., Van den Hout, W. B., Stiggelbout, A. M., Van de Velde, C. J., \& Kievit, J. (2004). Cost measurement in economic evaluations of health care: whom to ask? Medical Care, 42(8), 740-746.

van Ravesteijn, H., Grutters, J., olde Hartman, T., Lucassen, P., Bor, H., van Weel, C., et al. (2013). Mindfulness-based cognitive therapy for patients with medically unexplained symptoms: a cost-effectiveness study. Journal of Psychosomatic Research, 74(3), 197-205.

Van Vliet, I., \& De Beurs, E. (2007). Het Mini Internationaal Neuropsychiatrisch Interview (MINI). Een kort gestructureerd diagnostisch psychiatrisch interview voor DSM-IV en ICD-10 stoornissen [The Mini International Neuropsychiatric Interview (MINI). A short structured diagnostic psychiatric interview for DSMIV and ICD-10 disorders]. Tijdschrift voor Psychiatrie, 49(6), 5.
Ware, J. J., Kosinski, M., \& Keller, S. D. (1996). A 12-item short-form health survey: construction of scales and preliminary tests of reliability and validity. Medical Care, 34(3), 220-233.

Welte, R., Feenstra, T., Jager, H., \& Leidl, R. (2004). A decision chart for assessing and improving the transferability of economic evaluation results between countries. Pharmacoeconomics, 22(13), 857-876.

Zorginstituut Nederland (ZIN). (2016). Medicijnkosten. Retrieved from https://www.medicijnkosten.nl. Accessed July till September 2016.

Zorginstituut Nederland (ZIN). (2015). Kosteneffectiviteit in de praktijk [Cost-effectiveness analysis in practice]. Diemen.

Publisher's Note Springer Nature remains neutral with regard to jurisdictional claims in published maps and institutional affiliations. 